\title{
A Study on Causes and Effects of Migration from Rural to Urban: A Case Study of Bijapur Colony- Ligapayyankakadu, Mulki
}

\author{
Laveena D’Mello ${ }^{1}$, Meena Monteiro ${ }^{2}$ \\ ${ }^{1}$ Assistant Professor, Social Work Department, Srinivas Institute of Management Studies, \\ Mangalore, Karnataka, India. \\ ${ }^{2}$ Associate Professor, MSW Department, School of Social Work, Roshni Nilaya, Mangalore, \\ Karnataka, India \\ E-mail: lavynoronha@gmail.com
}

Type of the Paper: Research Case Study.

Type of Review: Peer Reviewed.

Indexed In: OpenAIRE.

DOI: http://dx.doi.org/10.5281/zenodo.1004672.

Google Scholar Citation: $\underline{\text { IJCSBE }}$

How to Cite this Paper:

D’Mello, Laveena., Monteiro, Meena. (2017). A Study on Causes and Effects of Migration from Rural to Urban: A Case Study of Bijapur Colony- Ligapayyankakadu, Mulki. International Journal of Case Studies in Business, IT and Education (IJCSBE), 1(2), 37-43. DOI: http://dx.doi.org/10.5281/zenodo.1004672.

International Journal of Case Studies in Business, IT and Education (IJCSBE)

A Refereed International Journal of Srinivas University, India.

(C) With Authors.

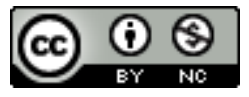

This work is licensed under a Creative Commons Attribution-Non Commercial 4.0 International License subject to proper citation to the publication source of the work.

Disclaimer: The scholarly papers as reviewed and published by the Srinivas Publications (S.P.), India are the views and opinions of their respective authors and are not the views or opinions of the S.P. The S.P. disclaims of any harm or loss caused due to the published content to any party. 


\title{
A Study on Causes and Effects of Migration from Rural to Urban: A Case Study of Bijapur Colony- Ligapayyankakadu, Mulki
}

\author{
Laveena D’Mello ${ }^{1}$, Meena Monteiro ${ }^{2}$ \\ ${ }^{1}$ Assistant Professor, Social Work Department, Srinivas Institute of Management Studies, \\ Mangalore, Karnataka, India. \\ ${ }^{2}$ Associate Professor, MSW Department, School of Social Work, Roshni Nilaya, Mangalore, \\ Karnataka, India \\ E-mail: lavynoronha@gmail.com
}

\begin{abstract}
Migration is the movement of people across a specified boundary for the purpose of establishing a new or semi-permanent residence. Migration is from a rural area to the urban area in search of new job avenues, improve their economic condition and to improve the standard of living once they go back to their native. Migration denotes a person living outside his or her native place especially from a rural area to urban. Many leave their homes because there are not enough employment opportunities, low yielding land, more family members depend on the small land, food, water, work or other fundamental requirements like health benefits, education. Another important aspect is that the consequences of environmental catastrophes, such as drought, floods, low prices for their products, disease to the product can also force thousands to leave their native countries. Today people are moving towards cities seeking employment opportunities. In this paper, the researcher wants to study about causes and effects of migration with the case study. The objectives are to know the reason for migration and the effects of their migration. 50 respondents were covered out of 1400 migrated people from Bijapura colony, Lingappayana Kadu, Mulky, under simple random sampling method. Questionnaires method was used to collect the data. Both primary and secondary data was included.
\end{abstract}

Keywords: Migration, Rural, Urban, Labour, Employment and economic condition.

\section{INTRODUCTION :}

Migration is a universal phenomenon and its social and economic implications have been widely recognized. It plays a significant role in molding the social, economic and other structural characteristics of the population of a country or region. Migration occurs when various factors operate together and the importance of factors responsible for migration varies from place to place based on development milieu. On the basis of settlement status of place of origin and rural to rural, rural to urban, urban to urban, urban to rural estimation, internal migration is classified into four types, namely. But with the passage of time, the volume of rural to urban migration has increased due to broadening gap in the levels of socio-economic development between rural and urban areas, especially in the developing nations of the world, because throughout the history, migration has been intimately related to economic and social development and it is often seen as the result of imbalances in the levels of development [1-4].

After independence, India has undergone rapid urbanization the pace of urbanization is not only due to the natural increase in population growth, but it has been mainly caused by the heavy influx of rural migrants in urban areas particularly in the large-sized cities and metropolises [5]. The main causes of heavy influx of rural migrants in urban areas are either due to the repulsive forces operating in the rural areas in the form of high rates of unemployment, poverty, low wages, small size of land holdings, lack of infrastructure development, or due to the attractive forces working in urban 
areas in the form of availability of jobs in factories, shops, offices, buildings and public services, facilities of vocational, technical and higher education, better medical service high wages, less arduous nature of work, expanding infrastructure facilities, civic amenities and facilities etc. There is no doubt that rural-urban migration stream affects the society at the origin, at destination and migrants themselves [6]. The rural-urban migration appears to be accelerating in spite of rising levels of urban unemployment and growing numbers of urban workers. The dramatic migration of people from rural areas to the urban centers not only poses a number of socio-economic and environmental problems in urban areas, but it also exerts an adverse impact on the rural areas due to the selectivity of migrants [7].

\section{CLASSIFICATION OF MIGRATION :}

People will migrate or immigrate out of the country permanently. So the migrations can be classified into 5 types. Each type can then be classified as either conservative or innovative. An innovative move is one in which the migrant undertakes a new way of life. A conservative move preserves an accustomed way of life in new surroundings [8,9]. Primitive Migration-in response to environmental conditions; usually undertaken by people at low levels of development, Forced Migration compulsory transfer of people by the government, Free Migration - individual movements for economic betterment, Mass Migration- large numbers, entire communities, moving without being fully informed on an individual basis of what to expect. So there are major two types of migration: one within the country and other is outside the county. When people migrate from one country to another country in large number for some political reason, it will be a great problem to that country. Similarly, when people move in large number to from rural area to urban area and land up in particular community, the slum will be generated which is a challenge to the Panchayat or the city corporation to provide basic amenities like water, accommodation, electricity, roads, transport and health facilities.

\section{CAUSES OF RURAL TO URBAN MIGRATION IN INDIA :}

In India, it reveals that majority of the rural migrants arrived in the urban areas due to social factors and male migration is more economically motivated than female migration. The migrant population, are migration with household, marriage, and education. The migration for marriage is another important social factor of rural to urban migration in the country. It is a type of obligatory migration in which a girl moves to her husband's place after marriage. It is, in general, highly female selective due to patriarch marriage system prevalent in the most parts of India. Education, though qualitatively a very significant social factor, and the wide-ranging impact of education is possibly the most important matter to be considered in inducing rural-urban migration. The segment of migrants mainly comprises young boys and girls belonging to relatively affluent families. Villages seldom have schools beyond primary standard while colleges and higher education centers are obviously confined to urban areas, but for the villagers, it is rather expensive to send their children to cities for higher education [10].

On the basis of the distance involved, the internal migration in India may be classified into three types: short, medium and long distance migrations, which are roughly indicative of the relationship between distance and migration (Bose 1974). The short-distance or intra-district migration is represented by persons born outside the place of enumeration but within the district of enumeration, medium distance or inter-district migration is consisted by persons born outside of the district of enumeration but within the state of enumeration, and lastly the long-distance or interstate migration is recorded as persons born in states (within the boundaries of India other than that of the state of enumeration. The socioeconomic causes of rural to urban migration may also change with the distance between the place of origin and destination. Therefore, the percentage distribution of socioeconomic causes of rural to urban migration in India based on the type of migration defining boundaries crossed in the act of migration. In short and medium distance migrations, social factors like marriage and migration with household are the major reasons for migration, while long-distance migration that is more economic motivated has been mainly for better work or employment opportunities in urban areas of the economically developed states of India. The migration with the household is one of the most important social factors of rural to urban 
migration in the country Excluding the states of Manipur, Bihar, Kerala and West Bengal, in all the other states and UTs the proportion of migration with all the other states and UTs the proportion of migration with household in the total migration is higher than the marriage migration. The reasons for migration can be divided into two main aspects, the so-called "push" and "pull" factors. Push factors are those in their old place which force people to move. For example, there may be civil wars or wars in general in the country, but political or religious oppression, climate changes, lack of jobs or simply poverty are all important push factors. Pull factors are factors in the target country which encourage people to move; these include peace and safety, a chance of a better job, better education, social security, a better standard of living in general as well as political and religious freedom.

\section{LABOR MIGRATION: CAUSES :}

Poor living conditions, violence and armed conflicts, environmental problems, a lack of economic perspectives and the growing gap between rich and poor countries: all these factors play their part. Global mobility and the new media likewise have a great influence on current migration trends. Poor living conditions Population grows, economic development stagnates Violence and the abuse of power forced to flee Rich industrialized states are becoming more accessible. The rich industrialized states are becoming more accessible: Tourism, television and the Internet all enhance the attractiveness of migration. They make the poorest aware of the wealth of the rich. The growth of air travel facilitates journeys to far-away industrialized countries. So far only a fraction of those willing to consider migration have actually been able to travel to their preferred destination on other continents. But this could soon change since successful emigrants transfer a considerable share of their income to their relatives at home. As a result, more and more people can afford to travel to distant countries. Asylum seekers prefer countries where many of their fellow-countrymen already live. In simple terms, this means: Migration begets further migration.

Rural-urban continuum is a process of socioeconomic interaction between the villages and the towns or cities. Many cultural traits are diffused from cities to the rural areas. For example, dress patterns like pants, shirts, ties, skirts, jeans, etc. diffuse from cities to the rural areas. Besides these, new thoughts, ideologies are also diffused from the cities to the rural areas due to increase in communication via radio, television, newspaper, etc. The urbanism, which is an urban way of life, emerges in the cities and gradually reaches to the rural areas, depending on their proximity to cities. The process of urbanization has not been an isolated phenomenon. At present, along with the whole gamut of occupational diversification, the spread of literacy, education, mass communication, etc, continuity between rural and urban areas has increased. Urban jobs and other amenities of living have become status symbols in the rural areas. Many modern techniques of agricultural development and many of the institutional frameworks for rural development also generate from the urban centers. The large-scale commercialization of agriculture has also been facilitated by the process of urbanization. Similarly, agricultural requirements for machinery have generated the growth of manufacturing units in urban areas [11].

Sociologists had earlier thought that there is a clear difference between the urban and the rural community. However gradually this concept of rural-urban dichotomy underwent a change some sociologists found that there was much individualism, lack of understanding, fear and suspicion even among the villagers, the peaceful village image of rural life took a severe blow. These studies indicated that the happy community type of existence in villages was not a fact. Remarkably the concept of the urban community also underwent a change in the 1950's. It was found that family made life close, informal and secure. That is to say, there do exist 'Urban villages.' This aspect of complex societies is very puzzling. Moreover there exist people who live in villages and work in towns. Neither the village nor the town can thus be thought of as a stereotype. And One thing is clear from above discussion is that the rural and urban life in complex society is not the opposite of one another. In fact, it could no longer be assumed that the environment determined any one type of association. However, this is not to say that rural-urban populations do not have any differences [12] 


\section{LABOR MIGRATION: CONSEQUENCES :}

Labor mobility is one of the key features of economic development and its characteristics are closely tied to the nature of this development. Historically, development is associated with unevenness and structural change, giving an impetus to the movement of workers from one region to another, and from one sector to another. Even within the macro-structural features which determine the supply of, and demand for, certain types of migrant labor, the pattern of migration depends on a host of factors determined by labor market characteristics, together with the individual, household and community level features, and the existence of social networks, among other things. These factors cumulatively determine the 'causes' of migration. On the other hand, labor migration plays a key role in influencing the pattern of development, through its impact on a host of economic and non-economic variables, both in the origin and destination areas [13].

Labor migration does not recognize borders-but borders, whether urban, state, or international influence migration through a host of policies and regulatory measures. A key distinction between internal and international migration is the existence of national regulatory frameworks such as immigration controls (which leads to a distinction between regular and irregular migration). But regulatory frameworks and restrictive policies also operate within nation states. Early development literature conceptualized labor migration as occurring from the rural to urban, agricultural to industrial, and informal to formal sectors. However, the workforce pattern has changed across the world in favor of the services sector, and the informal sector is more prominent today, both in developing and developed countries than it was twenty or thirty years ago. In developing countries, the informal sector is no longer conceived as a temporary destination for migrants but in most cases, as a final destination. The (changing) structural features of world capitalism have an important bearing on both internal and international migration.

The theme of labor migration will explore all types of labor migration - internal, inter-state, crossborder and international. It will encourage cross-disciplinary studies and papers based on both fieldwork and secondary data. The contributors should confine themselves to the issue of worker migration, as conventionally defined in SNA accounts, and to leave out those types of "forced labor" migration, which is not conventionally included in work but are covered in international conventions on forced labor and trafficking. The paper contributors should not be concerned with other forms of non-labor migration or with population mobility, which is important for an understanding urban growth $[14,15]$.

Though it will perhaps never be possible to stop migration completely, the approach should be of managing it in such a way that no ethnic or social frictions are created across the country. Rural areas across the country must have all the amenities to ensure that people of younger generation choose to remain in there instead of moving to the bigger cities. If they still decide to migrate to bigger cities, the choice should be dictated more by a spirit of exploration rather than a compulsion to move out due to lack of opportunities .

\section{MAJOR FINDINGS :}

Study on cause and effects of migrated people in Bijapur community, Mangalore reveal the various truths of migrated people. The people will migrate in large number to Bijapura colonies are from the various district of North Karnataka especially from Bellary, Bagalkot, Gulbarga, Raichur etc. The main intention for migration is to achieve something in their life by increasing the Socio-Economic condition. For this sake, they leave their family behind and come in search of a job.

Majority 34 percent respondents are belonging to the age group of 19-29 years and 64 percent respondents are male and remaining 36 percent of the respondents are above 30 years of age. 60 percent of the respondents are belonging to Hindu religion and speaking Kannada language and others with Hindi, Malayalam, Tulu language of their local area. 54 percent respondents are married and remaining 46 percent are young and unmarried. 44 percent respondents have completed just PUC and working as a coolie and 36 percent are completed SSLC and remaining 20 percent are illiterate. The majority is 74 percent respondents are from nuclear family and have minimum 6-8 members in the family. But the present situation is that in one house more than 30-35 members staying together with little partition based on rooms and cook separately. There is no proper ventilation, drainage 
system, electricity, and water. There is no cleanliness in the surrounding of the community. Alcoholism and gambling are common in this area. Chewing pan and other toxic components, smoking, spending lavishly for the festival is the common feature of this area. 50 Percent of the respondents prefer to go to movies and entertainment. Sometimes if they like the movie they screen the same movie for more than three times. Hardly few save money and send it to their native place to take care of their family. They have a bank account and 50 percent of the people will have BPL card. Some have even not visited their family for the past 4 years.

The majority is 64 percent respondents from Gulbarga and Bijapur district that is why they all will name it as Bijapur colony. And remaining is from other districts. 48 percent respondents have migrated especially for the search of job and employment and others have come to assist them, the subordinates and dependents in the family. The majority is 44 percent, respondents, doing construction work and they also face unemployment problem. They stay in this area. The middlemen take them in their private vehicle to the city to work as a laborer in different construction sites. Their wage is paid by the middlemen. And they take their share as a commission for each laborer.

The majority is 56 percent respondents feel good and they have identified themselves as migrates but other 44 percent respondents feel hesitate to mix with others. This is due to low self-esteem they are not ready to speak and mix well with the local people. They are introvert and maintain gap while doing the work. They have full trust on the middlemen who brought them here and gave employment. But those middlemen will exploit them by taking a commission for daily wages. The majority is 84 percent respondents not visiting their friends and relatives; in fact, they do not have friends inside the community or outside.

The majority is 48 percent respondents celebrating Hindu festivals and average four festivals. They want to get entertainment from celebrating the festival by having alcohol and taking continues leave especially during Ganesh Chaturthi. This festival will continue for 7- 9 days and those days they hardly go for work.

The majority is 62 percent respondent's children do not go to school regularly. 34 percent of the respondent's children are going to school at their native place and other 4 percent of the student goes to school regularly. This is clear that parents do not have any goal in life and same they want their children to work and earn living and not much importance is given to education. When the researcher explained the importance of education they gave reasons saying that they will send the children to school at their native place. By visiting the city and native place it is clear that they are not permanent in one place so they cannot give concentration to education. School dropouts are more in this area.

\section{CONCLUSION :}

The governments in the developing countries of the world have framed various policies to contain the rural-urban migration flows but, even then, it has not been possible to slow down the volume of ruralurban migration up to a remarkable level. The failure of the policies to curb the volume of rural-urban migration stream has been due to the lack of comprehensive studies regarding the factors which force the rural potential migrants to leave their places of origin and the forces which attract them to settle down in urban areas. Migration of the people sometimes implies a lack of permanent settlement, especially as a result of seasonal or periodic movement. When people wanted to achieve something life they lose many things like education, bond, culture and family life.

\section{SUGGESTIONS :}

Since the people are from very poor background and are not in a position to give good and higher education to their children, Government has to take initiative in providing free education for the children. Free education is not only the primary level but government as to think about giving free higher education also. While giving education it also as to consider the job opportunities. So NGO's, Government Organizations including parents have to give job-oriented education. The government has to create job opportunities in their native place so that we can reduce the migration. In the rural area the subsidized loan, for the rural people and special consideration should be given through varies schemes to increase the income and to start self-employment in their native place. 


\section{REFERENCES :}

[1] Chakrapani C. and Vijaya Kumar S. (1994). Migration Pattern and Occupational Change :a study of Palamur Labour in Andhra Pradesh. The Indian Journal of Social Work, 55 (1), 83-94.

[2] Simmons A. B. (1998). NAFTA, International Migration and Labour Rights. Labour, Capital and Society, 31 (1-2), 10-43.

[3] Barron M. A., and Rello F. (2000).The Impact of the Tomato Agro industry on the Rural Poor in Mexico. Agricultural Economics, 23, 289-297

[4] Gidwani V. (2000). The Quest for Distinction: a Reappraisal of the Rural Labour Process in Kheda District. Economic Geography, Gujarat, India.

[5] Taylor J. E. and Wyatt T. J. (1996). The Shadow Value of Migrant Remittance, Income and Inequality in a Household Farm Economy. The Journal of Development Studies, 32 (6), 899-912.

[6] Osella F. and Osella C. (2000). Migration, Money and Masculinity in Kerala. Journal of the Royal Anthropology Institute, (N.S).

[7] Breman J. (1993). Beyond Patronage and Exploitation: Changing Agraricalture Relations in South Gujarat. Oxford University Press, Delhi.

[8] Cederstrom T. (1990). Migrant Remittances and Agricultural Development. Culture and Agriculture, 40, 2-7.

[9] Davila A. (1986). The Seasonality of Apprehensions of Undocumented Mexican Workers. International Migration Review, 20 (4), 986-991

[10] Reichert J. S. (1981). The Migrant Syndrome: Seasonal US Wage Labour and Rural Development in Central Mexico. Human Organization, 40 (1), 56-66.

[11] Kumari T. A. H. and Tataji U. (1998). Seasonal Migration of Women Workers: Process, Patterns and Consequences. Indian Journal of Social Work, 59.

[12] Meena Monteiro, Laveena D’Mello, Dr. Govindaraju B. M. (2017). A Study on the Working Conditions of Sales Persons in a Garment Shop at Mangalore. International Journal of Case Studies in Business, IT and Education (IJCSBE), 1(1), 67-71.

[13] Anonymous (1988). Migrant Workers Super-exploitation and Identity. Economic and political weekly, 23 (23) 1152-1153.

[14] Rizvi S. M. H. and Hashim S. R. (1983). Patterns of Seasonal Migration A Study of a Tribal Area. Journal of the Maharaja Sayajirao University of Baroda, 31, 109-122.

[15] Balakrishna S. Rangacharyulu S.V. and Panduranga Rao J. (1981). Seasonal Migration of Agricultural Labour: a Study in East Godavari District, Andhra Pradesh. Behavioural Sciences and Rural Development, 4 (2).

[14] Breman J. (1996). Footloose Labour: Working in India Informal Economy, Cambridge University Press, Cambridge.

[15] Gentleman S. (1987) The Incorporation of Mexican Women in Seasonal Migration: a Study of Gender Differences. Hispanic Journal of Sciences, 9(3), 245-264.

$* * * * * * * * *$ 